\title{
Antimicrobial, Antioxidative, Elastase and Tyrosinase Inhibitory Effect of Supercritical and Hydrothermal Halopteris scoparia Extract
}

\author{
Soo HyeonHeo ${ }^{1}$, Su InPark ${ }^{2}$, Jinseo Lee ${ }^{3}$, Sung Won Jung ${ }^{4}$, Moon SamShin ${ }^{5}$

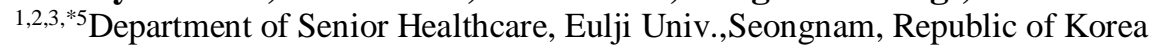 \\ ${ }^{4}$ R\&D Center, ACTIVON Co. Ltd., Suwon, Republic of Koreah_soo_h@naver.com ${ }^{1}$, sooo_30@naver.com² \\ dlwlstj97@ naver.com ${ }^{3}$, swjung1808@activon.kr ${ }^{4}$, msshin@eulji.ac.kr ${ }^{* 5}$
}

Article History: Received: 11 January 2021; Accepted: 27 February 2021; Published online: 5 April 2021

\begin{abstract}
To find out a good candidate of cosmetic source and screened for antimicrobial, antioxidant and whitening activities. In the antioxidant experiment, supercritical Halopteris scoparia extraction (SHE) and hydrothermal Halopteris scoparia extraction (HHE) were slightly different depending on the experimental method (Total polyphenol content measurement, DPPH radical scavenging ability, ABTS radical scavenging ability, and SOD-like activity) and in the enzyme experiment (Elastase, Tyrosinase inhibition activity), the supercritical extract was more effective. In supercritical fluid, Halopteris scoparia extracts showed good antimicrobial activity against Propionibacterium acnes, Staphylococcus aureus, Bacillus subtilis and Escherichia coli but hydrothermal extract had no effect about the rest of the strains. Therefore, it can be expected that the supercritical Halopteris scoparia extract with excellent antibacterial activity can be used as a cosmetic material.
\end{abstract}

Keywords: Halopteris scoparia, Seaweed, Supercritical fluid, Antimicrobia , Cosmetics

\section{Introduction}

Recognition of cosmetics is gradually deviating from the category of "products used to clean or beautify the human body and preserve skin or hair in good health", and attention is focused on how to grow younger and healthily with age. Accordingly, the emergence of functional cosmetics has emerged, and materials that are safe for the human body have been gradually developed, enabling the development of sanitary aid and functional cosmetics.

Hydrothermal extraction and solvent extraction are mainly used to obtain high purity functional extracts required in the cosmetics and food industry, and solvent extraction methods are used often to obtain various active ingredients. However, there are problems with solvents such as a skin irritation and environmental pollution caused by large amounts of waste solvents. Interest in supercritical fluid extraction process using supercritical carbon dioxide is increasing as an environment-friendly alternative technology for compensate and improve the shortcomings of existing natural effective extraction process. Extracting supercritical fluids uses carbon dioxide that is harmless to the human body. Supercritical fluid is defined as "A fluid that is heated to a temperature higher than critical temperature and greatly increased in density as pressure increases above critical pressure," which has a unique characteristic that differs from conventional solvents by having the properties of both liquids and gases at the same time and is a heavy fluid that fills a confined space like a machine [1]. For supercritical carbon dioxide, it is possible to extract the active ingredient for almost any range of molecular weight. Currently, studies are actively conducted on various natural extracts using supercritical carbon dioxide.

Marine organisms that live in the oceans have been found to contain several compounds that distinguish them from terrestrial organisms, marine life by showing the recent sponges, polychaeta and the extract of seaweed bioactive has attracted attention as a raw material for the development of cosmetic. Representative compounds exhibit physiological activity in the current marine organisms to extract is known as tannins, terpenes, phenol, halogen, and catechin [2]. Seaweed extracts contain natural compounds involved in antioxidants, antibacterial, anticancer, anti-inflammatory, anti-blood coagulation and immune - control actions, so they are a leading class of new drug development that can be used for disease prevention and treatment [3-5]. In this context, Halopteris scoparia, species of phaeophycean, is already known to limit the expansion of adipose tissues by inhibiting pre-adipocyte differentiation.

Therefore, this study intends to evaluate the antibacterial and antioxidant properties of Halopteris scoparia as a cosmetic material and to provide basic data for the development of cosmetic materials based on this.

\section{Materials andExperiments}

\subsection{Instruments and reagents}

The equipment and reagents used for each experiment are as follows. The solutions used for the polyphenol, DPPH test used in the antioxidant and antibacterial tests were obtained from Sigma Aldrich (USA). R6 (hexa-Darginine) was obtained from Dermafirm Co. (Seongnam, Korea). The equipment used in the experiment is as follows. Supercritical fluid extraction (ARI instrument, Namyangju, Korea), Absorption spectrophotometer (SYNERGY HTX multi-mode reader, Bio Tek, Seoul, Korea), Centrifugal separator (Supra-25K, Hanil Scientific Inc., Gimpo, Korea). Thermostat (Changshin Science, Seoul, Korea), High pressure processor (Microfluidizer, Picomax, Seoul, Korea), Particle size analyzer (Nanoctrac Flex, DREAM Co., Suwon, Korea), 
Particlemetrix (Stabino® Paticle Charge Mapping, DREAM Co., Suwon, Korea), Franz Diffusion Cells and Systems (PermeGear, USA)

\subsection{Sample extraction}

In the hydrothermal extraction method, purified water was added to the Halopteris scoparia powder and extracted for 4 hours in a thermostat at $80^{\circ} \mathrm{C}$ and filtered and freeze dried. In the supercritical extraction method, the pressure of the extractor was set to 350 bar and the temperature to $60^{\circ} \mathrm{C}$. The pressure of the separator was set to $40 \mathrm{bar}$, the temperature was set to $25^{\circ} \mathrm{C}$, and the flow rate of $\mathrm{CO} 2$ was extracted at $60 \mathrm{~mL} / \mathrm{min}$ for 150 minutes.

\subsection{Total polyphenol content measurement}

Quantification of polyphenol was measured by Folin-danis [6]. To $100 \mu \mathrm{L}$ of the Folin-Ciocalteu reagent, add $100 \mu \mathrm{L}$ of the diluted sample solution and reacted at room temperature for 3 minutes. $100 \mu \mathrm{L}$ of Na2CO3 solution was added and the absorbance was measured at $760 \mathrm{~nm}$ with an ELISA reader. The average value of polyphenol contents by concentration was calculated. The calibration curves were quantitatively analyzed using garlic acid as a standard.

1) DPPH radical scavenging ability

\subsection{Antioxidant activity measurement}

The effect about DPPH radical scavenging was measured by Blois method [7]. To $100 \mu \mathrm{L}$ of the extract solution, $120 \mu \mathrm{L}$ of $0.45 \mathrm{mM}$ 2,2-diphenyl -1-picrylhydrazyl solution was added and reacted in the dark room for 30 minutes. Absorbance was measured at $530 \mathrm{~nm}$ with an ELISA reader.

DPPH radical scavenging activity $(\%)$

$=[($ Absorbance of DPPH solution - absorbance of samples $) /$ absorbance of DPPH solution $] \times 100$

2) ABTS radical scavenging ability

The effect about ABTS radical scavenging was measured by Re method [8, 18]. The ABTS radical cation (ABTS+) was produced by reacting $7.2 \mathrm{mM}$ stock solution ABTS with $2.64 \mathrm{mM}$ potassium persulphate (final concentration) and allowed the mixture to stand in the dark for at least 24 hours at room temperature before use. The ABTS+ solution was diluted to an absorbance $0.7 \pm 0.05$ at $745 \mathrm{~nm}$. Absorbance was measured 20 minutes after the initial mixing of different concentrations of the extracts. The ABTS+ decolorisation capacity of the extracts were compared with the standard ascorbic acid.

ABTS radical scavenging activity $(\%)$

$=[($ Absorbance of ABTS solution - absorbance of samples $) /$ absorbance of ABTS solution $] \times 100$ 2.5 Measurement of Superoxide Dismutase (SOD)

SOD-like activity was performed by modifying Marklund's method [9]. The experiment was carried out using SOD Assay Kit (BCBV5418). $20 \mu \mathrm{L}$ of buffer solution and $20 \mu \mathrm{L}$ of enzyme working solution were added to 20 $\mu \mathrm{L}$ of each sample solution, and incubation was carried out at $37^{\circ} \mathrm{C}$ for 20 minutes. The absorbance at $420 \mathrm{~nm}$ was measured by an ELISA reader.

SOD similar activity $(\%)$

$=[1-($ Absorbance in the sample addition group / absorbance in the no additives $)] \times 100$

\subsection{Measurement of elastase}

Elastase inhibitory activity was measured by Cannell [10]. The experiment was carried out using EnzCheck® elastase Assay Kit (E-12056). 1x Reaction buffer was used to dilute the Halopteris scoparia extract sample and incubated in a 96-well black plate using $100 \mathrm{mg} / \mathrm{L}$ DQ elastin solution and $0.2 \mathrm{U} / \mathrm{mL}$ elastase for 30 minutes at room temperature. Absorbance was measured at $485 \mathrm{~nm}$ excitation and $528 \mathrm{~nm}$ emission fluorescence with an ELISA reader.

Inhibition rate of elastase $(\%)$

$=[1-($ Absorbance in the sample addition group / absorbance in the no additives $)] \mathrm{x} 100$

2.7 Measurement of tyrosinase activity

Tyrosinase activity was modified by the method of Kubo [11]. $0.1 \mathrm{M}$ sodium phosphate buffer (pH 6.5) and 50 $\mu \mathrm{l}$ with purified water to $40 \mu \mathrm{l}, 2000 \mathrm{U}$ mushroom tyrosinase (Sigma, T3824) $5 \mu \mathrm{l}$ pre-manufacturing a total of 95 $\mu \mathrm{l}$ to minutes after the extract $5 \mu \mathrm{l}$ was placed. $0.03 \%$ L-tyrosine $50 \mu \mathrm{l}$ was added and incubated at $37^{\circ} \mathrm{C}$ for 10 minutes. Kojic acid was used as positive control. Absorbance was measured at $475 \mathrm{~nm}$ with an ELISA reader.

Inhibition rate of tyrosinase $(\%)=\left[100-\left(\left(b^{-} b^{\prime}\right) /\left(a-a^{\prime}\right)\right) \times 100\right]$ 
a: Absorbance after reaction of blank

b: Absorbance after sample liquid reaction

a', b': Absorbance measured by replacing with buffer solution

\subsection{Antimicrobial experiment}

The disc diffusion test was performed to determine the antimicrobial activity of Halopteris scoparia [12]. Staphylococcus aureus (S. aureus), Escherichia coli (E. coli), Bacillus subtilis, and Propionibacterium acnes (P. acnes)were purchased from KCM and KCTC. The strains Staphylococcus aureus, Escherichia coli and Bacillus subtilis were cultured in Muller-Hinton medium at $37^{\circ} \mathrm{C}$ for 24 hours, re-cultured once, and then absorbed at 600 $\mathrm{nm}$ using a spectrophotometer. Propionibacterium acnes was incubated in a sealed container for 72 hours, reincubated once, and then absorbed at $600 \mathrm{~nm}$ using a spectrophotometer. The culture conditions are shown in Table (1).

Table 1. List of strains and cultivation condition used for antimicrobial experiments

\begin{tabular}{|c|c|c|c|}
\hline Strains & Media & Temperature $\left({ }^{\circ} \mathbf{C}\right)$ & Time (h) \\
\hline Staphylococcus aureus (ATCC6538) & MH & 37 & 24 \\
\hline Escherichia coli (ATCC23726) & MH & 37 & 24 \\
\hline Bacillus subtilis (ATCC19659) & MH & 37 & 24 \\
\hline Propionibacterium acnes (ATCC6919) & RC & 37 & 48 \\
\hline
\end{tabular}

2.9 Statistical processing

All experiments were repeated 3 times. All values were expressed as mean and standard deviation and the difference between the values was analyzed by t-test, one-way analysis of variance (ANOVA) with Post hoc(LDS) respectively.

\section{Results}

\subsection{Yield}

Halopteris scoparia was extracted with hydrothermal and supercritical. Each yield was $12.92 \%$ in $\mathrm{HHE}$ (Hydrothermal Halopteris scoparia extraction) and $0.1 \%$ in SHE (Supercritical fluid Halopteris scoparia extraction)

\subsection{Total polyphenol content}

To measure the total polyphenol content, the results of the comparison of the extraction process of Halopteris scoparia extract are shown in Table 2.

\subsection{Antioxidant efficacy of Halopteris scoparia}

1) DPPH radical scavenging ability

DPPH radical is a method of measuring the activity of a hydrogen donor. When they get electron from phenolic compounds or aromatic amines, the color is turned purple to yellow by proton-radical scavengers [13]. The antioxidant activity of the extracts was shown between $0.63 \sim 5 \mathrm{mg} / \mathrm{ml}$. In $5 \mathrm{mg} / \mathrm{ml}$, the radical scavenging activity was $67 \%$ in hydrothermal extraction and 94\% in supercritical extraction Figure (1).

2) ABTS radical scavenging ability

ABTS radical cation is a deep blue-green radical that reacts with antioxidants and is characterized by discoloration by light green. The antioxidant effect of ABTS free radicals produced by the reaction of potassium persulfate is measured by the degree of discoloration of the radical-specific cyan color to light green [14]. The antioxidant activity of the extracts was shown between $0.63 \sim 5 \mathrm{mg} / \mathrm{ml}$. The concentration - dependent results were showed and IC50 of HHE is $61.39 \mathrm{ppm}$ and IC50 of SHE is $384.58 \mathrm{ppm}$ Figure (2).

\subsection{Superoxide Dismutase (SOD) measurement}

SOD-like activity assay is an antioxidant activity assay using color development by automatic oxidation [15]. The substances that inhibit superoxide in the samples used in the experiment can inhibit the oxidation by oxidation in the presence of SOD or SOD-like active substances. In the SOD (Superoxide dismutase) - like experiments, IC50 of HAE is 364.57 ppm Figure (3).

Table 2. Total polyphenols of extracts from Halopteris scoparia

\begin{tabular}{|c|c|c|}
\hline Samples & Method & Total polyphenols (mg/g) \\
\hline HHE & Hydrothermal extract & $20.42 \pm 6.09$ \\
\hline SHE & Supercritical fluid extract & $9.99 \pm 4.45$ \\
\hline
\end{tabular}


Antimicrobial, Antioxidative, Elastase and Tyrosinase Inhibitory Effect of Supercritical and Hydrothermal Halopteris scoparia Extract

Values represent the mean \pm SD of three independent experiments.HHE : Hydrothermal Halopteris scoparia extraction,SHE : Supercritical fluid Halopteris scoparia extraction

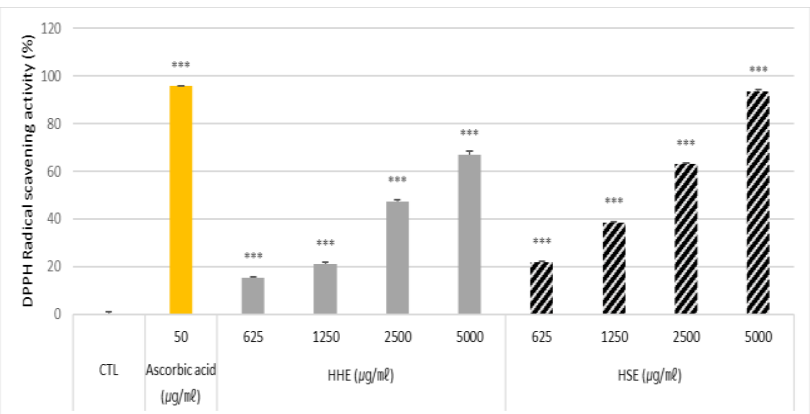

Figure1. Scavenging effect of Halopteris scoparia on DPPH assays

Values represent the mean $\pm \mathrm{SD}$ of three independent experiments. Positive control: Ascorbic acid $50 \mu \mathrm{g} / \mathrm{ml}$ to $96 \%$. $* \mathrm{p}<0.05, * * \mathrm{p}<0.01, * * * \mathrm{p}<0.001$. HHE: Hydrothermal Halopteris scoparia extraction SHE : Supercritical fluid Halopteris scoparia extraction

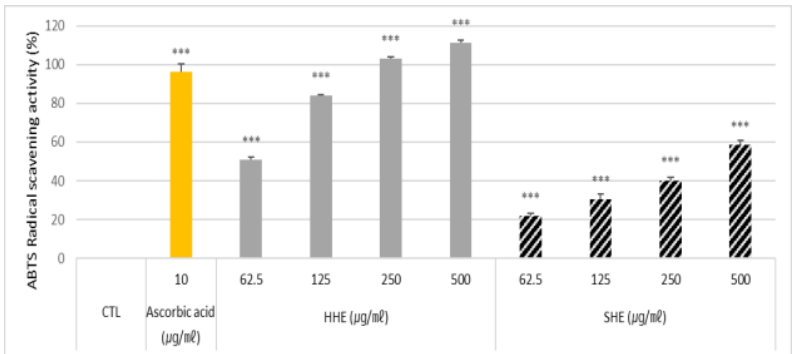

Figure 2. Scavenging effect of Halopteris scoparia on ABTS assays

Values represent the mean $\pm \mathrm{SD}$ of three independent experiments. ${ }^{*} \mathrm{p}<0.05, * * \mathrm{p}<0.01, * * * \mathrm{p}<0.001 . \mathrm{HHE}$ : Hydrothermal Halopteris scoparia extraction. SHE : Supercritical fluid Halopteris scoparia extraction

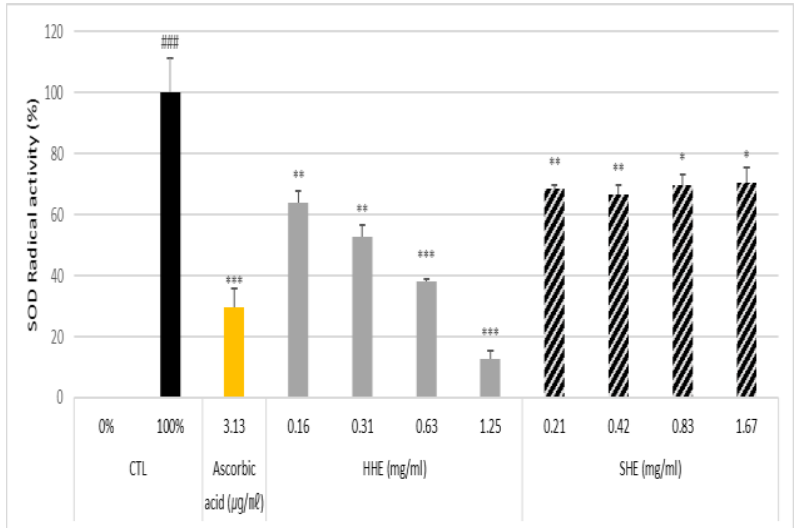

Figure 3. Scavenging effect of Halopteris scoparia on SOD assays

Values represent the mean $\pm \mathrm{SD}$ of three independent experiments. $* \mathrm{p}<0.05, * * \mathrm{p}<0.01, * * * \mathrm{p}<0.001$. HHE : Hydrothermal Halopteris scoparia extraction. SHE : Supercritical fluid Halopteris scoparia extraction 3.5Measurement of elastase

The elastase which is presented in the dermis of the skin is an enzyme capable of degrading various proteins including fibronectin, collagen and elastin which maintains elasticity of the skin in the dermis [16]. The elastase inhibitory effect which is effective for improving the wrinkles of the skin was measured according to the concentration dependent and IC50 of HHE is 1419 ppm and IC50 of SHE is 1875 ppm in Figure (4). 


\subsection{Measurement of tyrosinase activity}

Melanin is a pigment produced by melanomas, one of the cell organelles. Melanin is produced by the action of various enzymes such as tyrosinase, tyrosinase-related protein 1 (TRP1) and tyrosinase-related protein 2 (TRP2) in melanomas [17]. Among them, tyrosinase is a major regulatory enzyme that plays a role in the oxidation of tyrosine to DOPA quinone after being hydrolyzed with DOPA and is related to melanin. The lowest tyrosinase activity of $47 \%$ was observed at the concentration at $667 \mathrm{mg} / \mathrm{ml}$ of SHE in Figure (5).

3.7 Antimicrobial experiment

The antimicrobial test was conducted three times using the paper disc method. The results of the clear zone measurement are shown in Table (3). As a result of the antimicrobial test, the supercritical fluid Halopteris scoparia extraction had antimicrobial effect in the four strains. In the case of Propionibacterium acnes strain, the largest clear zone of $23.00 \pm 1.00 \mathrm{~mm}$ was found at the concentration of $20 \mathrm{mg} / \mathrm{ml}$. In the other hand, in experiments with the same conditions, hydrothermal Halopteris scoparia extraction had no effect in all strains.Melanin is a pigment produced

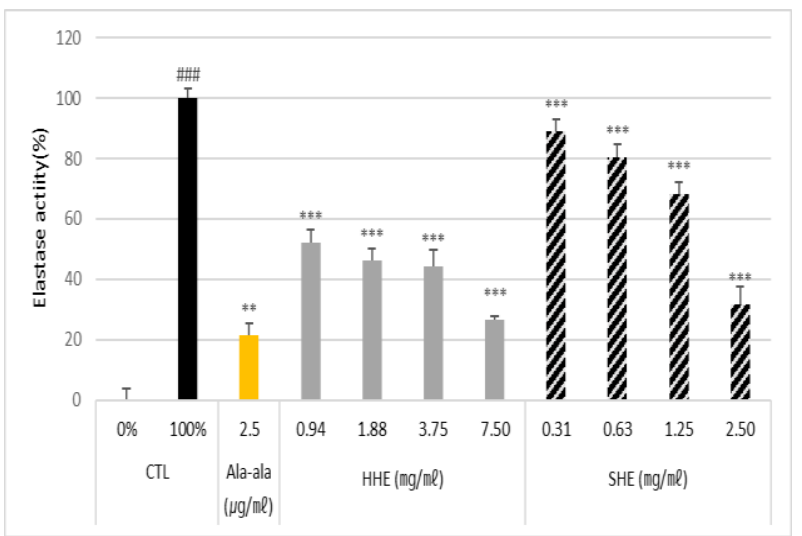

Figure 4. Scavenging effect of Halopteris scoparia on elastase assays

Values represent the mean $\pm \mathrm{SD}$ of three independent experiments. $* \mathrm{p}<0.05$, ** $\mathrm{p}<0.01, * * * \mathrm{p}<0.001$. HHE : Hydrothermal Halopteris scoparia extraction. SHE : Supercritical fluid Halopteris scoparia extraction

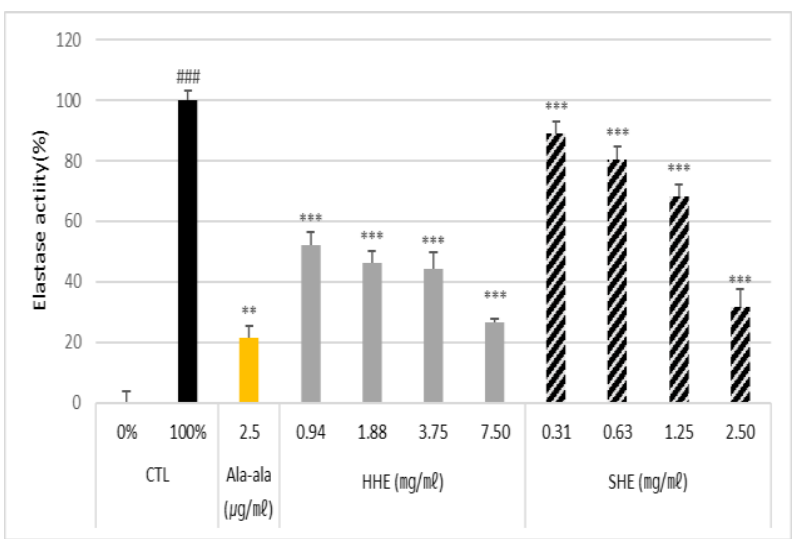

Figure 5. Scavenging effect of Halopteris scoparia on tyrosinase assays

Values represent the mean $\pm \mathrm{SD}$ of three independent experiments. ${ }^{*} \mathrm{p}<0.05$, **p $<0.01$, ***p $<0.001$. HHE : Hydrothermal Halopteris scoparia extraction. SHE : Supercritical fluid Halopteris scoparia extraction

Table 3. The effect of supercritical fluid Halopteris scoparia extract amount on area of clear zone

\begin{tabular}{|c|c|c|c|c|}
\hline \multirow{2}{*}{ Strains } & \multicolumn{4}{|c|}{ Clear zone(mm) } \\
\cline { 2 - 5 } & $\begin{array}{c}\mathbf{2 0} \\
\mathbf{m g} / \mathbf{m l}\end{array}$ & $\begin{array}{c}\mathbf{1 0} \\
\mathbf{m g} / \mathbf{m l}\end{array}$ & $\begin{array}{c}\mathbf{5} \\
\mathbf{m g} / \mathbf{m l}\end{array}$ & $\begin{array}{c}\mathbf{2 . 5} \\
\mathbf{m g} / \mathbf{m l}\end{array}$ \\
\hline $\begin{array}{c}\text { S. } \\
\text { aureus }\end{array}$ & $\begin{array}{c}9.20 \\
\pm 0.26^{\mathrm{a}}\end{array}$ & - & - & - \\
\hline
\end{tabular}


Antimicrobial, Antioxidative, Elastase and Tyrosinase Inhibitory Effect of Supercritical and Hydrothermal Halopteris scoparia Extract

\begin{tabular}{|c|c|c|c|c|c|}
\hline E. & \multicolumn{2}{|c|}{$\begin{array}{c}11.00 \\
\pm 0.10^{\mathrm{a}}\end{array}$} & $\begin{array}{c}11.70 \\
\pm 0.61^{\mathrm{a}}\end{array}$ & $\begin{array}{c}11.63 \\
\pm 0.55^{\mathrm{a}}\end{array}$ & $\begin{array}{c}10.83 \\
\pm 0.29^{\mathrm{a}}\end{array}$ \\
\hline coli & \multicolumn{2}{|c|}{$\begin{array}{c}12.90 \\
\pm 0.26^{\mathrm{a}}\end{array}$} & $\begin{array}{c}13.00 \\
\pm 0.17^{\mathrm{a}}\end{array}$ & $\begin{array}{c}9.77 \\
\pm 0.59^{\mathrm{a}}\end{array}$ & - \\
Babillus & \multicolumn{2}{|c|}{$\mathrm{S}$} & $\mathrm{S}$ & $\mathrm{S}$ & $\mathrm{S}$ \\
\hline \multirow{3}{*}{$P}$. & $\mathrm{H}$ & 17.00 & 12.03 & 11.83 & 9.17 \\
\cline { 2 - 6 } acnes & 12.30 & $\pm 1.00^{\mathrm{a}}$ & $\pm 0.15^{\mathrm{a}}$ & $\pm 0.21^{\mathrm{a}}$ & $\pm 0.06^{\mathrm{a}}$ \\
\hline
\end{tabular}

${ }^{\mathrm{a}}$ Growth inhibition line, H: Hydrothermal Halopteris scoparia extraction. S: Supercritical fluid Halopteris scoparia.

Clear zone for methyl paraben(positive control) is $13.10 \pm 0.10 \mathrm{~mm}$ at $20 \mathrm{mg} / \mathrm{ml}$ only in P.acnes strain.

\section{Conclusions}

This study was conducted to evaluate physiological activity of Halopteris scoparia extract. After extraction with Halopteris scoparia using hydrothermal and supercritical carbon dioxide, various physiological activities were examined. The total concentration of polyphenol compounds was determined to be $20.43 \mathrm{mg} / \mathrm{g}$ of hydrothermal Halopteris scoparia extract (HHE) and $9.99 \mathrm{mg} / \mathrm{g}$ of supercritical Halopteris scoparia extract (SHE). In DPPH (2,2-diphenyl-1-picrylhydrazyl) radical scavenging assay, ascorbic acid was used as positive antioxidant control. The percentage of inhibition and IC50 were measured. The IC50 of HHE is $2823 \mathrm{ppm}$ and the IC50 of SHE is $1833 \mathrm{ppm}$. In ABTS (2,2-azino-bis(3- ethylbenzothiazoline - 6 - sulfonic acid) diammonium salt) radical scavenging assay, ascorbic acid was used as positive antioxidant control. The percentage of inhibition and IC50 were measured. The IC50 of HHE is 61ppm and the IC50 of SHE is $385 \mathrm{ppm}$. The elastase inhibitory assay showed concentration dependence and the IC50 of HHE is 1419 ppm and the IC50 of SHE is $1875 \mathrm{ppm}$. In mushroom tyrosinase inhibition experiments, tyrosinase inhibition of SHE was $47 \%$ at 667 $\mathrm{mg} / \mathrm{mL}$. In the antimicrobial experiments, maximum clear zones of SSE represented $17.00 \mathrm{~mm}$ in Propionibacterium acnes, $12.90 \mathrm{~mm}$ in Bacillus subtilis, $11.00 \mathrm{~mm}$ in Escherichia coli, $9.20 \mathrm{~mm}$ in Staphylococcus aureus. And maximum clear zones of SHE represented $12.30 \mathrm{~mm}$ in Propionibacterium acnes, but hydrothermal extract had no effect about the rest of the strains.

Therefore, it can be expected that the supercritical fluid Halopteris scoparia extract with excellent antibacterial activity can be used as a cosmetic material.

\section{Acknowledgment}

This study was supported by the Bio \& Medical Technology Development Program of the National Research Foundation (NRF) funded of the Ministry of Science \& ICT (2017M3A9D8048416).

\section{References}

1. Lee, Y. W. (2003). Design of Particles using Supercritical Fluids, Korean Journal of Chemical Engineering, 41(6), 679-688.

2. Konig, G. M. (2006). Natural products from marine organisms and their associated microbes. Chembiochem, 7(2), 229-238.

3. Oh, Y. S., Lee, I. K., \& Boo, S. M. (1990). An annotated account of Korean economic seaweeds for food. medical and industrial uses, Korean journal of phycology, 5(1), 57-71

4. Kim, Y. M., Kim, D. S., \& Choi, Y. S. (2004). Anticoagulant activities of brown seaweed extracts in Korea. Korean Society of Food Science and Technology, 36(6), 1008-1013.

5. Duan, Z. J., Zhang, W. W., Li, X. M., \& Wang, B. G. (2006). Evaluation of antioxidant property of extract and fractions obtained from a red alga, P olysiphonia urceolata. Food chemistry, 95(1), 3743.

6. Folin, O., \& Denis, W. (1912). On phosphotungstic - phosphomolybdic compounds as color reagents. Journal of Biological Chemistry, 12, 239-243.

7. Blois, M. S. (1958). Antioxidant determinations by the use of a stable free radical. Nature, 181, 1199-1200.

8. Re, R., Pellegrini, N., Proteggente, A., Pannala, A., Yang, M., \& Rice-Evans, C. (1999). Antioxidant activity applying an improved ABTS radical cation decolorization assay. Free Radical Biology and Medicine. 26, 1231-1237.

9. Marklund, S., \& Marklund, G. (1974). Marklund. Involvement of the superoxide anion radical in the autoxidation of pyrogallol and a convenient assay for superoxide dismutase. European Journal of Biochemistry, 47(3), 469-474.

10. Cannell, R. J., Kellam, S. J., Owsianka, A. M., \& Walker, J. M. (1988). Results of a large scale screen of microalgae for the production of protease inhibitors. Planta Medica, 54(1), 10-14

11. Kubo, I., \& Kinst-Hori. (1999). Favonols from saffron flower: tyrosinase inhibitory activity and inhibition mechanism. Journal of Agricultural and Food Chemistry, 47(10), 4121-4125. 
12. Ko, M. O., Kang, H. J., Hwang, J. H., \& Yang, K. W. (2018). Screening of the antibacterial effects by ethanol extracts from natural plant in Jeju against Propionibacterium acnes. Journal of Society of Cosmetic Scientists of Korea, 44(1), 59-66.

13. Shin, S. (2019). Biological activities on phenolic compounds of Japanese anise (Illicium anisatum L) extracts. The Internal Journal of Advanced Cultural Technology, 7(3), 120-125.

14. Natella, F., Maldini, M., Leoni, G., \& Scaccini, C. (2016). Glucosinolates redox activities : Can they act as antioxidants ?. Food Chemistry, 149(15), 226-232.

15. Kim, J. G., \& Son, J. H. (1996). The quantity of superoxide dismutase (SOD) in fresh royal jelly. Korea Beekeeping Association, 11(1), 8-12.

16. Kligman, D. (2000). Cosmeceuticals. Dermatologic Clinics, 18, 609-615.

17. Briganti, S., Camera, E., \& Picardo, M. (2003). Chemical and instrumental approaches to treat hyperpigmentation. Pigment Cell \& Melanoma Research, 16(2), 101-110.

18. Aksoy, B. (2019). Determination of map literacy of undergraduate geography students. Review of International Geographical Education Online, 9(3), 591-603. 